\title{
Spinal and Supraspinal Control of the Direction of Stepping during Locomotion
}

\author{
Pavel E. Musienko, ${ }^{1,2}$ Pavel V. Zelenin, ${ }^{3}$ Vladimir F. Lyalka, ${ }^{3}$ Yury P. Gerasimenko, ${ }^{1}$ Grigory N. Orlovsky, ${ }^{3}$ \\ and Tatiana G. Deliagina ${ }^{3}$ \\ ${ }^{1}$ Pavlov Institute of Physiology, 100034 St. Petersburg, Russia, ${ }^{2}$ Center for Neuroprosthetics and Brain Mind Institute, School of Life Sciences, Swiss Federal \\ Institute of Technology (EPFL), CH-1015 Lausanne, Switzerland, and ${ }^{3}$ Department of Neuroscience, Karolinska Institute, SE-17177 Stockholm, Sweden
}

Most bipeds and quadrupeds, in addition to forward walking, are also capable of backward and sideward walking. The direction of walking is determined by the direction of stepping movements of individual limbs in relation to the front-to-rear body axis. Our goal was to assess the functional organization of the system controlling the direction of stepping. Experiments were performed on decerebrate cats walking on the treadmill with their hindlimbs, whereas the head and trunk were rigidly fixed. Different directions of the treadmill motion relative to the body axis were used $\left(0, \pm 45, \pm 90\right.$, and $\left.180^{\circ}\right)$. For each direction, we compared locomotion evoked from the brainstem (by stimulation of the mesencephalic locomotor region, MLR) with locomotion evoked by epidural stimulation of the spinal cord (SC).

It was found that $\mathrm{SC}$ stimulation evoked well coordinated stepping movements at different treadmill directions. The direction of steps was opposite to the treadmill motion, suggesting that this direction was determined by sensory input from the limb during stance. Thus, SC stimulation activates limb controllers, which are able to generate stepping movements in different directions. By contrast, MLR stimulation evoked well coordinated stepping movements only if the treadmill was moving in the front-to-rear direction. One can conclude that supraspinal commands (caused by MLR stimulation) select one of the numerous forms of operation of the spinal limb controllers, namely, the forward walking. The MLR can thus be considered as a command center for forward locomotion, which is the main form of progression in bipeds and quadrupeds.

\section{Introduction}

In vertebrates, nervous mechanisms at different levels of the CNS participate in the control of locomotion. Stepping movements of individual limbs are generated by spinal neuronal circuits (limb controllers; Orlovsky et al., 1999). Supraspinal centers activate these spinal mechanisms and adapt their activity to different behavioral tasks and environmental conditions (for review, see Sherrington, 1906; Grillner, 1975; Shik and Orlovsky, 1976; Arshavsky et al., 1986).

One important task of the locomotor system is the control of the direction of stepping movements of individual limbs relative to the front-to-rear body axis. Most bipeds and quadrupeds, in addition to the main form of locomotion, forward walking, are also capable of backward and sideward walking (Stein et al., 1986;

\footnotetext{
Received Aug. 6, 2012; revised 0ct. 8, 2012; accepted 0ct. 13, 2012

Author contributions:P.E.M.,P.V.Z.,Y.P.G., G.N.O., and T.G.D. designed research;P.E.M.,P.V.Z., Y.P.G., and T.G.D. performed research;P.E.M., P.V.Z., V.F.L., G.N.O., and T.G.D. analyzed data; P.E.M., P.V.Z., Y.P.G., G.N.O., and T.G.D. wrote the paper.

This work was supported by grants from the National Institutes of Health R01 NS-064964, from the Christopher and Dana Reeve Foundation, from the Swedish Research Council (no. 11554) to T.G.D.; the Russian Foundation for Basic Research Grants (11-04-01669) and a grant from the President of Russian Federation (Мк-5684.2012.4) to P.E.M.; the Russian Foundation for Basic Research Grants (10-04-01172a, 11-04-1274-0FI-M-2011) to Y.P.G.; and by a grant from the Swedish Research Council (no. 21076) to P.V.Z. We thank Dr. Russell Hill for valuable comments on this manuscript, Medynja Kutueva for the excellent technical assistance during surgeries and experiments and for animal care, and Vyacheslav Kilimnik and Alexandr Savochin for engineering support and help in the development of the experimental setup.

Correspondence should be addressed to Dr. T. G. Deliagina, Department of Neuroscience, Karolinska Institute, SE-17177 Stockholm, Sweden. E-mail: Tatiana.Deliagina@ki.se.

DOI:10.1523/JNEUROSCI.3757-12.2012

Copyright $\odot 2012$ the authors $\quad 0270-6474 / 12 / 3217442-12 \$ 15.00 / 0$
}

Buford and Smith, 1990; Buford et al., 1990; Rossignol, 1996; Deliagina et al., 1997; Zelenin et al., 2011). Also, the steps deviated from the direction of progression are used for correcting perturbations of balance during forward walking (Karayannidou et al., 2009; Musienko et al., 2012). Steps with a lateral component can also be initiated by large postural perturbations during standing (Karayannidou et al., 2009). The mechanisms controlling the step direction are mostly unknown. A goal of the present study was to assess functional organization of the system controlling the direction of stepping, as well as the role of different CNS levels in this control. For this purpose, we compared locomotion of decerebrate cats evoked by stimulation of the brainstem and by stimulation of the spinal cord (SC).

It is known that electrical stimulation of the mesencephalic locomotor region (MLR) evokes locomotion in the decerebrate cat (Shik et al., 1966; Shik and Orlovsky, 1976; Jordan, 1986; Garcia-Rill and Skinner, 1987a,b). This stimulation activates locomotor mechanisms of the brainstem and SC (for review, see Arshavsky et al., 1986). Locomotion in the decerebrate cat can also be evoked by epidural electrical SC stimulation near its dorsal midline (Iwahara et al., 1992; Musienko et al., 2007, 2012). SC stimulation also evokes locomotion in spinal subjects (Gerasimenko et al., 2003), and it was suggested that it activates spinal mechanisms of stepping (limb controllers; Orlovsky et al., 1999) through the afferents of the dorsal roots (Gerasimenko et al., 2005). Thus, one can suggest that SC stimulation in the decerebrate cat primarily activates the spinal limb controllers, and much less affects the supraspinal mechanisms. 
In the present study, we compared MLR- and SC-evoked locomotion on the treadmill moving in different directions. We have found that at any direction of the treadmill, SC stimulation evoked well coordinated stepping movements opposite to the treadmill motion. In contrast, MLR stimulation evoked coordinated stepping movements only when the treadmill was moving backward. These findings suggest that SC stimulation activates limb controllers, and they generate stepping movements in different directions on the basis of sensory input coming from the limb during stance. In contrast, MLR activates only one of the numerous forms of operation of the spinal limb controllers, namely, the forward walking.

A brief account of this study was published in abstract form (Deliagina et al., 2012).

\section{Materials and Methods}

Subjects. Experiments were performed on nine adult cats of either sex (weighting 2.2-4.0 kg). All procedures were conducted according to the European Community Council Directive (November 24, 1986, 86/609/ EEC) in accordance with a protocol approved by the Animal Care Committee of the Pavlov Institute of Physiology, St. Petersburg, Russia, and followed the guidelines of the National Institute of Health Guide for the Care and Use of Laboratory Animals.

Surgical procedures. The cats were anesthetized deeply with a mixture of xylazine ( $1 \mathrm{mg} / \mathrm{kg}$, i.m.) and ketamine ( $40 \mathrm{mg} / \mathrm{kg}$, i.m.), and supplemented $30-50 \%$ of the initial dose if necessary. The level of anesthesia was monitored based on applying pressure to the paw (to detect limb withdrawal), as well as by checking the size and reactivity of the pupils. The trachea was cannulated and carotid arteries were ligated. The animal was decerebrated at the precollicular-postmammilar level. A laminectomy was performed in the lumbar area. Bipolar electromyographic (EMG) electrodes ( $0.2 \mathrm{~mm}$ flexible stainless steel Teflon-insulated wires) were implanted bilaterally into the gastrocnemius lateralis (Gast; ankle extensor), tibialis (Tib; ankle flexor), adductor femoris (Add; hip extensor and adductor), and gluteus medius (Glut; hip extensor and abductor) as described previously (Gerasimenko et al., 2009). Our reason for recording these particular muscles was that Gast and Tib take part in the longitudinal component of step, while Glut and Add also take part in the lateral component of step. Anesthesia was discontinued after the surgical procedures, and the experiments were initiated $2-3 \mathrm{~h}$ thereafter.

During the experiment, the rectal temperature and mean blood pressure of the animal were continuously monitored and were kept at $37 \pm$ $0.5^{\circ} \mathrm{C}$ and $>80 \mathrm{mmHg}$.

Experimental design. The experimental design is shown in Figure 1. The head of the decerebrate animal, the vertebral column, and the pelvis were fixed in a rigid frame (Fig. 1A), ensure straight trunk configuration. Such trunk configuration is similar to that observed in intact cats during forward walking, but differs from that assumed by animals during backward walking (Buford et al., 1990). However, for standardization of conditions for comparison, we provided equal "posture" for all locomotor tests. There was no support surface under the forelimbs. During evoked locomotion of the hindlimbs, the forelimbs usually did not move rhythmically or performed weak stepping movements in the air. The hindlimbs were positioned on the treadmill with two separate belts (left and right) moving at the same speed $(0.5 \mathrm{~m} / \mathrm{s})$ and referred to below as "treadmill belt." The distance between the treadmill belt and the fixed pelvis was $21-25 \mathrm{~cm}$ (depending on the animal size), which determined a hemiflexed limb configuration in the middle of stance typical for walking. The treadmill could be oriented at different angles $(\alpha)$ relative to the longitudinal body axis; six values of $\alpha$ were used: $0^{\circ}, 45^{\circ} \mathrm{R}, 45^{\circ} \mathrm{L}, 90^{\circ} \mathrm{R}$, $90^{\circ} \mathrm{L}$, and $180^{\circ}$. For each orientation, the treadmill velocity vector is indicated by arrow in Figure $1 B$. In addition, we tested the ability of the cat to perform stepping in place on the stopped treadmill and in air (with no support surface under the hindlimbs).

Locomotion was evoked by stimulating either MLR or SC. The stimulation started in 2-3 s after onset of the treadmill belt motion. We used parameters of stimulation that were found optimal in the previous stud- ies (Shik et al., 1966; Musienko et al., 2007, 2012). For MLR stimulation, a bipolar electrode (two $150 \mu \mathrm{m}$ wires insulated except for the tips and separated by $0.5 \mathrm{~mm}$ ) was inserted into the brainstem area (Horsly-Clark coordinates $\mathrm{P} 2, \mathrm{R} / \mathrm{L} 4, \mathrm{H} 0$ ) by means of a micromanipulator (Fig. $1 \mathrm{~A}$, MLR-stim). We used the following parameters of stimulation: frequency, 30 pulses per second (pps); pulse duration, 0.5-1 ms; and current, 50$200 \mu \mathrm{A}$. For epidural SC stimulation, a ball electrode $(d=0.5 \mathrm{~mm})$ was positioned on the dura mater in the middle of the dorsal surface of the spinal cord at the L5 level (Fig. 1A, SC-stim). We used the following parameters of stimulation: frequency, $5 \mathrm{~Hz}$; pulse duration, $0.2-0.5 \mathrm{~ms}$; and current, $100-300 \mu \mathrm{A}$.

In each locomotor test, the rear view and the side view of the walking cat were recorded by two video cameras ( 25 frames/s), which were synchronized with EMG recordings. In addition, in the tests with forward and backward walking, we recorded the anterior-posterior (A-P) limb movements (by means of two mechanical sensors, one of which, Limb-R, is shown in Fig. $1 A$ ), as well as the vertical forces developed by each of the limbs (by means of two force plates positioned under the left and right moving belts; Fig. $1 A$, FP).

Data analysis. The signals from the EMG electrodes and from the position sensors were amplified, digitized with a sampling frequency of 5 (EMGs) and $1 \mathrm{kHz}$ (sensors), and recorded on a computer disk using the data-acquisition and analysis software (Power-1401/Spike2; Cambridge Electronic Design). The EMGs were rectified (see Fig. 2, $A, B$ ). During locomotion evoked by SC stimulation, the EMG signals contained large responses to each stimulating pulse (coming at 5 pps, Figs. $2 B, 8 B, D, F, 9 D$ ). These responses were removed during analysis with a custom-written program triggered by stimulating pulses. The EMG signals were then averaged for each of the 100 bins of the step cycle that was normalized to 1.0 (over a sequence of 5-20 steps). The beginning of the swing phase was taken as the cycle onset.

The video recordings were analyzed frame by frame. From the rear view (Fig. 1A, Video-1) and/or from the side view (Fig. 1C, Video-2) it was easy to establish whether the foot was on the ground (i.e., the limb was in the stance phase of its step cycle) or the foot was lifted (i.e., the limb was in the swing phase). During the stance phase, the vertical foot coordinate $Z=0$ and the foot trajectory could be entirely characterized by two coordinates, $X$ and $Y$ (Fig. 1C). A grid of coordinates (that compensated for distortions of perspective) was applied to the image of the treadmill area (Fig. 1C). Using this grid, foot coordinates were measured in sequential frames. If there were no displacements of the foot in relation to the moving belt, the foot trajectory throughout the stance would be a straight line parallel to the velocity vector (Fig. $1 C$, thick gray line), with equal interpoint distances. We considered such results as evidence that the step was adapted to the treadmill motion. If there were foot displacements during the stance, the foot trajectory would deviate from the treadmill belt velocity vector, indicating that the step was not adapted to the treadmill motion. To estimate quantitatively the deviation of the foot trajectory from the velocity vector, for each step we determined "approximated stance trajectory" (the line connecting the initial and final stance positions), and then calculated the angle between this line and the velocity vector ( $\mathrm{S}-\mathrm{V}$ angle).

During the swing phase, the foot was lifted above the ground, but its vertical coordinate $Z$ could not be precisely measured with our methods. Therefore, the foot trajectory during swing could be characterized only roughly in $X / Y$ coordinates.

All quantitative data in this study are presented as mean \pm SD. Student's $t$ test was used to characterize the statistical significance when comparing different means; the significance level was set at $p=0.05$.

\section{Results}

Only the cats exhibiting well coordinated forward walking on backward moving treadmill during MLR stimulation and/or SC stimulation were tested under other conditions using the parameters of stimulation that were effective for forward walking. In two animals (cat 2 and cat 4), walking at different conditions was examined during MLR-evoked locomotion and SC-evoked locomotion of the same vigor (i.e., with similar values of contact forces and EMG amplitudes). In other cats, the quality of walking was better with one of the stimulation sites; correspondingly, in 
two cats, only MLR-evoked locomotion was investigated, and in five other cats, we tested only SC-evoked locomotion. The data obtained from cat 4 will be used to illustrate locomotion in different directions evoked by MLR and SC stimulation.

\section{Treadmill angle $0^{\circ}$}

\section{MLR and SC stimulation}

Forward walking (treadmill angle $\alpha=0^{\circ}$, Fig. $1 B$ ) of cat 4 evoked by MLR stimulation is illustrated in Figure $2 A$, and that evoked by SC stimulation in Figure $2 B$. The two locomotor patterns were mostly similar. In both cases, stepping limb movements were rather uniform, with the step cycle duration of $0.7-0.8 \mathrm{~s}$, the peak contact force $\sim 0.7 \mathrm{~kg}$, and similar step length. The right and left limbs were stepping in antiphase.

The EMG patterns were also similar in these two tests: the muscles with extensor function (Gast, Add, Glut) were active during the stance phase of the limb, and the flexor (Tib) was active during the swing phase. The EMG signals during SCevoked locomotion contained large shortlatency responses to stimulating pulses, coming at a frequency of 5 pps (Figs. $2 B$; Fig. $8 B, D, F, 9 D)$. Figure $7\left(0^{\circ}\right)$ shows averaged EMGs during MLR-evoked $(A)$ and SC-evoked $(B)$ forward walking. One can see that the EMG patterns were mostly similar.

Figure $3 A$ shows a trajectory of the right foot in $X / Y$ coordinates (Fig. 1C) during one step cycle of forward walking evoked by MLR stimulation. In the stance phase (filled circles, 1-11), the foot moved from the extreme front position to the extreme rear position along a straight trajectory, in parallel both to the velocity vector (large black arrow) and to the body axis (thick gray line), at the speed equal to that of the treadmill. In the swing phase, the foot rapidly returned to the extreme front position (empty circles, 12-18).

To evaluate variability of stepping limb movements in sequential steps, we approximated the stance trajectory by a straight line connecting the initial and final stance positions. Figure $3 B$ shows the approximated stance trajectories for 10 sequential steps of the right limb; the orthogonal bars indicate double SD values for $X$ and $Y$ coordinates, at the initial and final stance positions. In each trajectory, the $Y$ value at these two positions was the same, indicating that the trajectories were parallel to the velocity vector and to the body axis; the mean value of the S-V angle in cat 4 was $0^{\circ}$ (red interrupted line). Stance trajectories of the left limb were also parallel to the velocity vector (one of these trajectories is shown in Fig. 3A). Similar results were obtained in all tested cats (Fig. 4, bar 1; Table 1, column $0^{\circ}$ ). Figure 3, $C$ and $D$, illustrates forward walking in cat 4 evoked by SC stimulation. Again, stance trajectories were found to be parallel to the velocity vector. Similar results were obtained in all tested cats: the mean value of the $\mathrm{S}-\mathrm{V}$ angle was $0^{\circ}$ (Fig. 4, bar 2; Table 1 , column $0^{\circ}$ ).

The alignment of the stance trajectory and the velocity vector during both MLR-evoked and SC-evoked forward walking suggested that the foot contacted the same spot on the moving tread- mill belt throughout the stance phase. For this reason, we considered the forward walking as a form of locomotion well adapted to the treadmill motion.

\section{Treadmill angle $90^{\circ}$}

MLR stimulation

The MLR-evoked locomotion on the treadmill moving sideward in cat 4 had some characteristics similar to those of forward walking in this cat: the step cycle duration was 0.7-0.9 s, and steps of opposite limbs alternated. The step length in the leading (performing outward step) limb was slightly larger than in trailing (performing inward step) limb $(17.9 \pm 3.0 \mathrm{~cm}$ against $16.1 \pm 3.1$ $\mathrm{cm}$, respectively). Large variability of the step direction and amplitude was observed. The limbs frequently collided with each other, causing additional distortion in their stepping.

Figure $5 \mathrm{~A}$ shows the trajectory of the left foot during one step cycle of walking on the treadmill positioned at $\alpha=90^{\circ} \mathrm{R}$. In the stance phase, the foot moved from the initial stance position (point 1) rightward at the velocity of the treadmill motion (points $1-5)$, suggesting that this movement was caused by the moving treadmill belt. The foot decelerated (points 5-8) and then started moving backward despite the rightward motion of the treadmill (points 8-16), suggesting that this movement was caused by active contraction of limb muscles. After reaching the final stance position (point 16), the swing phase began, and the foot rapidly returned to its initial position (point 22). The shape of stance trajectory in different cycles was highly variable, from the twosection shape (with one section parallel to the treadmill velocity vector, and another one parallel to the trunk axis, as illustrated in Fig. 5A), to the one-section shape trajectory laying between the 


\section{MLR stimulation}

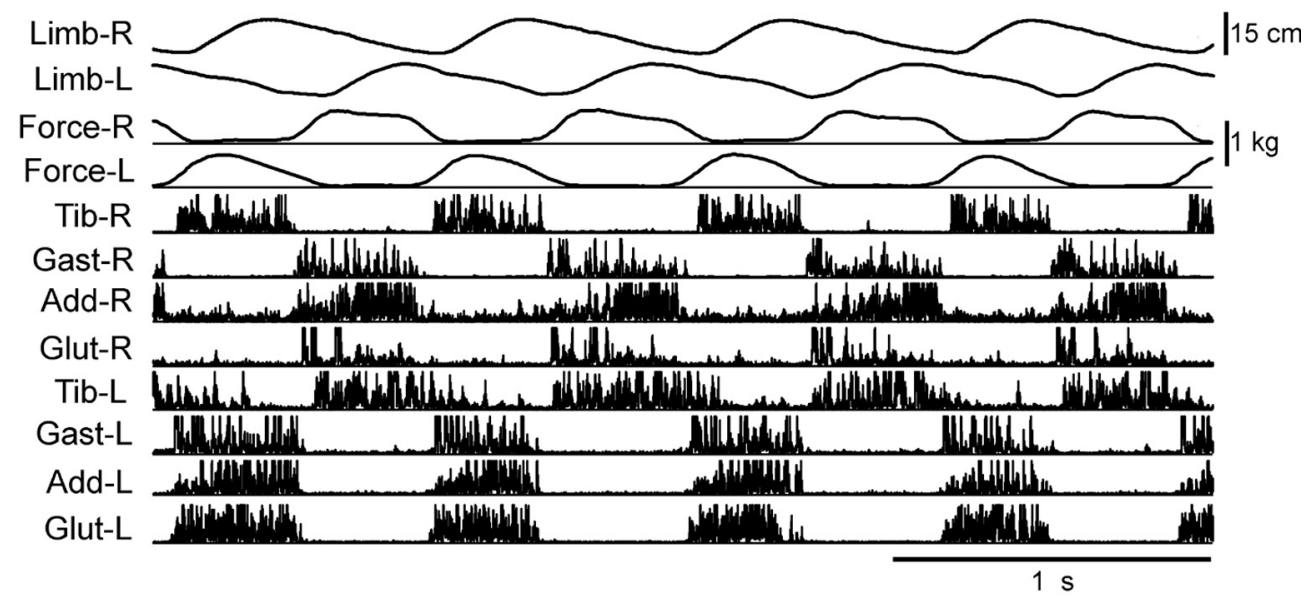

B SC stimulation

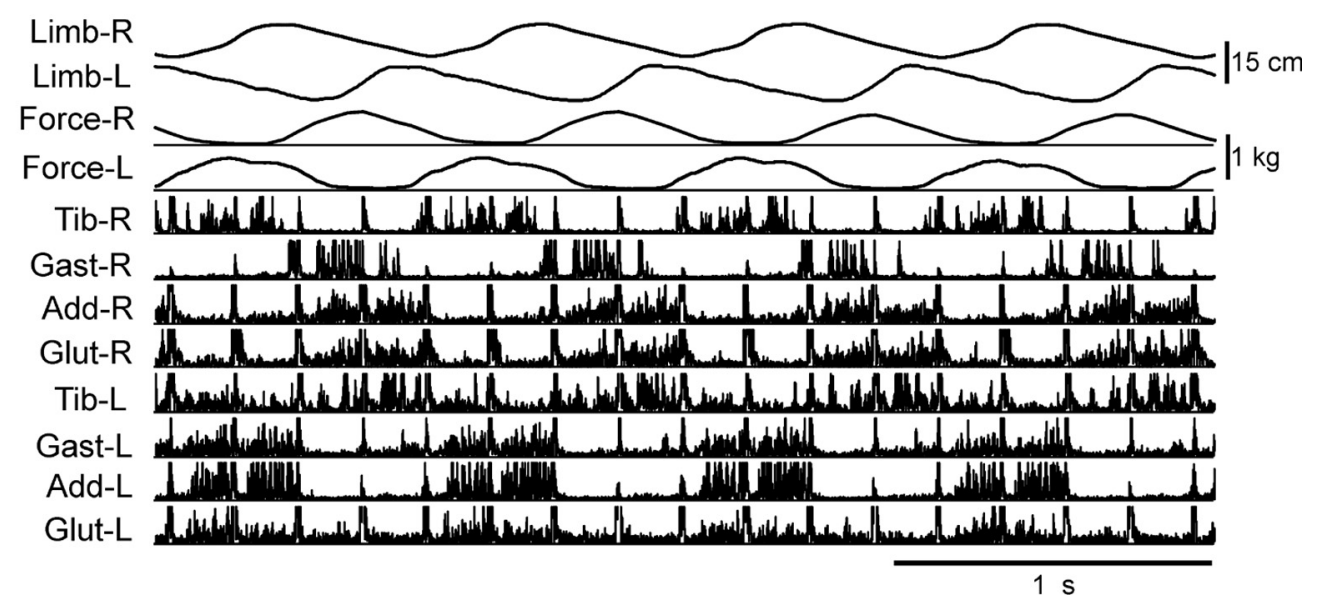

Figure 2. Forward locomotion in cat 4 (treadmill angle $\alpha=0^{\circ}$ ) evoked by MLR stimulation $(\boldsymbol{A})$ and SC stimulation ( $\boldsymbol{B}$ ). Recording of movements of the right and left limbs (Limb-R and Limb-L), contact forces (Force-R and Force-L), and EMGs.

trunk axis and treadmill velocity vector (illustrated in Fig. 6A). Figure $5 B$ shows the approximated stance trajectories (see Materials and Methods) for 10 sequential steps of the left limb; the orthogonal bars indicate double SD values for $X$ and $Y$ coordinates at the initial and final stance positions. One can see a large variability of these trajectories. All trajectories were considerably inclined in relation to the velocity vector. The mean angle of the stance trajectory in cat 4 was $40 \pm 15^{\circ}$ (red interrupted line). Similar results were obtained in all tested cats: the mean value of the S-V angle was $39 \pm 14^{\circ}$ (Fig. 4, bar 5 ; Table 1 , column $90^{\circ}$ ). This finding suggests that, during the stance phase, the foot contacted different spots on the moving treadmill belt, i.e., the limb was sliding on the support surface because the direction of active foot movement differed from that of support surface movement. For this reason, we considered MLR-evoked walking as a form of locomotion poorly adapted to the sideward treadmill motion (Table 1, column $\left.90^{\circ}\right)$. It seems likely that the limb controllers generated the motor pattern of forward walking rather than the pattern of sideward walking, which caused dramatic distortions of stepping movements (see Discussion).

\section{SC stimulation}

The SC-evoked walking on the treadmill moving sideward in cat 4 had some characteristics similar to those in the MLR-evoked walking: the step cycle duration was $0.7-0.8 \mathrm{~s}$, steps of the opposite limbs alternated, and limb movements were asymmetrical, with longer steps in the leading limb $(14.0 \pm 1.4 \mathrm{~cm})$ and shorter in trailing limb $(10.2 \pm 0.8 \mathrm{~cm})$. Also, the stepping limbs could collide with each other. However, the locomotor limb movements with SC stimulation were much more consistent than with MLR stimulation.

Figure $5 C$ shows a trajectory of the left foot during one step cycle of SC-evoked locomotion on the rightward moving treadmill. In the stance phase (points 1-11), the foot moved rightward from the initial stance position (point 1) to the final stance position (point 11) along a straight trajectory, in parallel to the velocity vector and perpendicular to the body axis, at the velocity equal to that of the treadmill. In the swing phase, the foot rapidly returned to the extreme front position (points 12-20). In addition, Figure $5 C$ shows an approximated stance trajectory of the right foot, which was also parallel to the velocity vector. It is important to note that there was some distance $(\sim 7 \mathrm{~cm})$ between the stance trajectories of the right and left feet. Due to this distance, the left limb performed its lateral steps in 
the more rostral position than the right limb (Fig. 5E), which helped the limbs to reduce collisions with each other.

Figure $5 F$ shows extreme positions of the leading (left) and trailing (right) limbs in the stance phase (in $X-Z$ coordinates). One can see a significant asymmetry in stepping movements of the two limbs.

Figure $5 D$ shows 10 approximated stance trajectories of the left foot (cat 4) during SC-evoked walking on the rightward moving treadmill. The variability of trajectories was much smaller than in the MLR-evoked walking (Fig. 5B). All stance trajectories were parallel to the velocity vector; the mean value of the $S-V$ angle in cat 4 was $0^{\circ}$ (red interrupted line). Similar results were obtained in all tested cats (Fig. 4, bar 6; Table 1, column $90^{\circ}$ ). On this reason, one can conclude that the SCevoked locomotion was well adapted to the sideward treadmill motion, and can be termed the sideward walking. A striking difference between MLR- and SC-evoked walking was also manifested in different EMG patterns (see below).

\section{Treadmill angle $45^{\circ}$ \\ MLR stimulation}

Most characteristics of MLR-evoked walking in cat 4 on the treadmill positioned at $\alpha=45^{\circ}$ were similar to those obtained at $\alpha=90^{\circ}$ : the step cycle duration was $0.7-0.8 \mathrm{~s}$, steps of the opposite limbs alternated, and limb movements were symmetrical (the step amplitude was $17.0 \pm 3.1 \mathrm{~cm}$ in the leading limb against $16.8 \pm 1.93 \mathrm{~cm}$ in the trailing limb). A large variability of the step direction and amplitude was also observed. The limbs frequently collided with each other, causing disruption in their stepping.

Figure $6 A$ shows an example of the left foot trajectory during one step cycle of cat 4 (treadmill angle $\alpha=45^{\circ} \mathrm{R}$ ). In the stance phase, the foot moved from the extreme front position (point 1) to the extreme rear position (point 15) along an almost rectilinear trajectory. The angle of this trajectory relative to the body axis was $24^{\circ}$, i.e., it was between the trunk angle $\left(0^{\circ}\right)$ and the treadmill angle $\left(45^{\circ}\right)$. The foot movement along the trajectory was uneven, with an increased velocity in the middle of stance. In the swing phase, the foot moved from the extreme rear position (point 15) to the extreme front position (point 22), which was close to the starting position (point 1).

The shape of stance trajectories at the treadmill angle $\alpha=$ $45^{\circ}$ was as variable as at $\alpha=90^{\circ}$. Figure $6 B$ shows the approximated stance trajectories for 10 sequential steps of the left limb. One can see a large variability of stance trajectories. All individual trajectories were inclined in relation to the velocity vector. The mean angle of the stance trajectory relative to this vector in cat 4 was $21 \pm 5^{\circ}$ (red interrupted line). Similar results were obtained in all tested cats: the mean value of the $\mathrm{S}-\mathrm{V}$ angle was $17 \pm 6^{\circ}$ (Fig. 4 , bar 3 ; Table 1 , column $45^{\circ}$ ).

\section{$\underline{\text { Treadmill }}^{\circ}$}

\section{MLR stimulation}

B $\times(\mathrm{cm})$

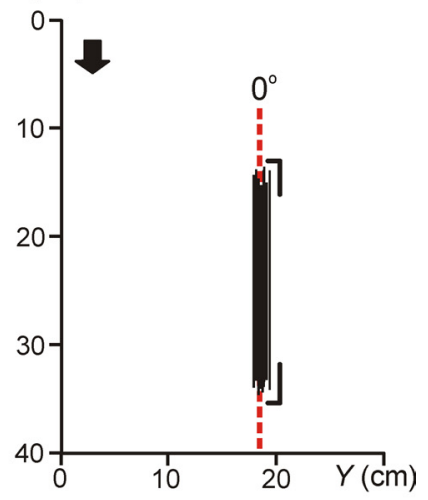

\section{SC stimulation}

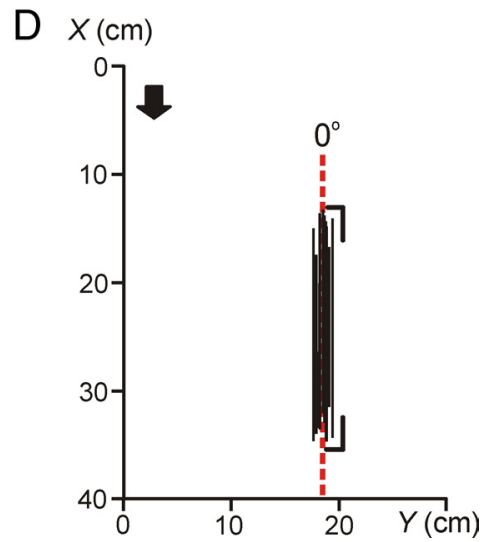

Figure 3. Forward locomotion in cat 4 (treadmill angle $\alpha=0^{\circ}$ ) evoked by MLR stimulation $(\boldsymbol{A}, \boldsymbol{B})$ and SC stimulation $(\boldsymbol{C}, \boldsymbol{D})$. $\boldsymbol{A}$ is shown by the red interrupted line. The orthogonal bars indicate double SD values for $X$ and $Y$ coordinates, at the initial and final stance positions. Position of the cat's head, trunk, pelvis, and limbs relative to the treadmill area is indicated. The large arrow designates the belt velocity vector. Symbols: filled circles, stance; empty circles, swing.

Figure 4. Characteristics of stance trajectory during MLR-and SC-evoked locomotion. The mean value ( $\pm S D$ ) of $S-V$ angles is shown for the backward $\left(\alpha=0^{\circ}\right)$, diagonal $\left(\alpha=45^{\circ}\right)$, and sideward $\left(\alpha=90^{\circ}\right)$ direction of treadmill motion. The data for $45^{\circ} \mathrm{R}$ and $45^{\circ} \mathrm{L}$, as well as for $90^{\circ} \mathrm{Rand} 90^{\circ} \mathrm{L}$, were pooled together. In bars indicated by arrows, this angle was close to zero (within measurement errors). Number of animals and data points in each average (bars 1-6) were as follows: 1, 4 and 138; 2, 7 and $102 ; 3,3$ and 160;4, 4 and 83; 5,3 and 156; and 6, 4 and 90 . 
Table 1. Proportion of animals with walking adapted to different directions of treadmill motion

\begin{tabular}{llrrr}
\hline & \multicolumn{4}{l}{ Treadmill direction } \\
\cline { 2 - 5 } Stimulation & $0^{\circ}$ & $45^{\circ}$ & $90^{\circ}$ & $180^{\circ}$ \\
\hline MLR & $100 \%(4 / 4)$ & $0 \%(0 / 3)$ & $0 \%(0 / 3)$ & $0 \%(0 / 4)$ \\
SC & $100 \%(7 / 7)$ & $100 \%(4 / 4)$ & $100 \%(4 / 4)$ & $57 \%(4 / 7)$ \\
\hline $\begin{array}{l}\text { A cat was considered as adapted to a given treadmill direction if it was walking, and the mean value of the } S \text {-V angle } \\
\text { was less than } 5^{\circ} .\end{array}$
\end{tabular}

\section{Treadmill $90^{\circ} \underline{R}$}

\section{MLR stimulation}
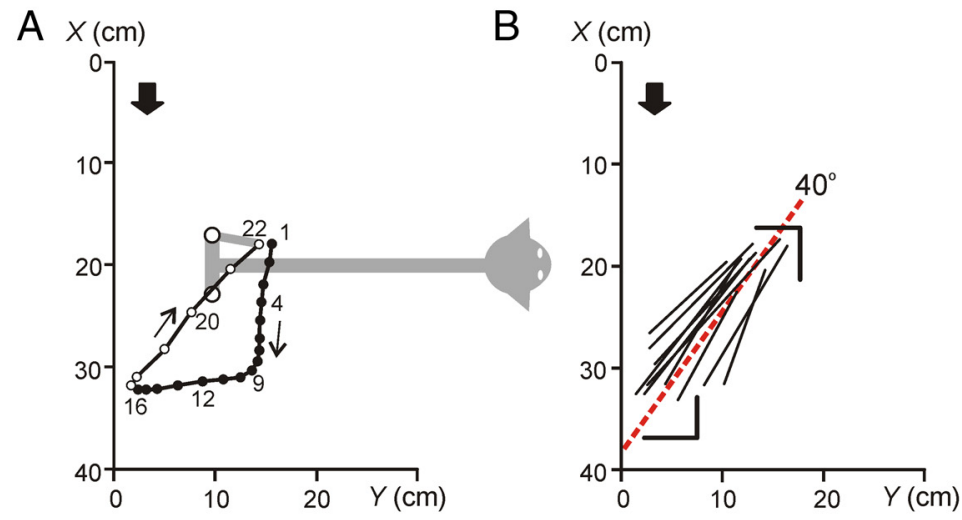

SC stimulation

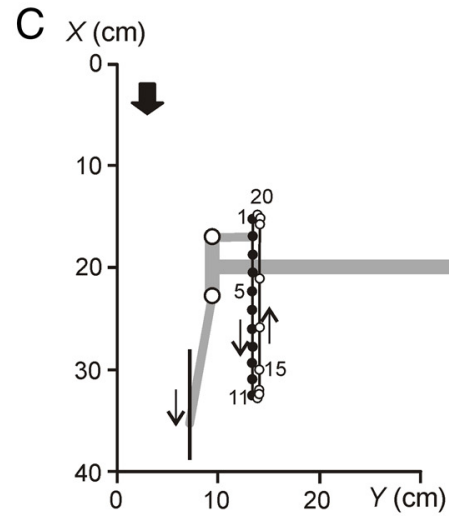

D $x(\mathrm{~cm})$
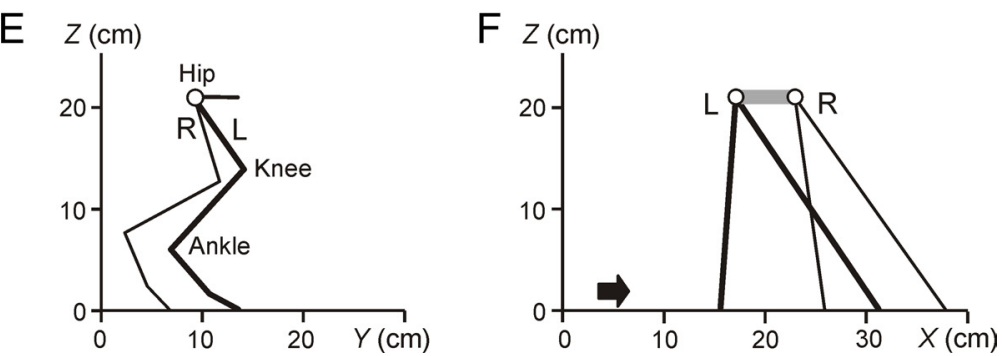

Figure 5. Locomotion evoked by MLRstimulation $(\boldsymbol{A}, \boldsymbol{B})$ and SC stimulation $(\boldsymbol{C}, \boldsymbol{D})$ in cat 4 on the treadmill moving sideward $\left(\alpha=90^{\circ} \mathrm{R}\right)$. $\boldsymbol{A}, \boldsymbol{C}$, Sequential positions of the left foot during one step cycle. In $\boldsymbol{C}$, the approximated stance trajectory of the right foot is also shown. $\boldsymbol{B}, \boldsymbol{D}$, Approximated stance trajectories in 10 sequential step cycles of the left limb, as well as the mean value of their S-V angles (red interrupted line). $\boldsymbol{E}$, Configuration of the left $(\mathrm{L})$ and right (R) limbs in the mid-stance (in $Y$ - $Z$ coordinates). $\boldsymbol{F}$, Extreme positions of the $L$ and $R$ limbs in the stance phase (in X-Z coordinates). Leading and trailing limbs (performing outward and inward step, respectively) are shown by thick and thin lines, respectively. Symbols and designations as in Figure 3.

\section{SC stimulation}

The SC-evoked walking on the treadmill positioned at $\alpha=45^{\circ}$ in cat 4 was in some respects similar to that evoked by MLR stimulation: the step cycle duration was $0.7-0.8 \mathrm{~s}$, steps of the opposite limbs alternated, and limb movements were asymmetrical, with longer steps in the leading limb $(15.5 \pm 1.0 \mathrm{~cm})$ and shorter in the trailing limb $(10.7 \pm 0.9 \mathrm{~cm})$. Also, the stepping limbs could collide with each other. However, the motor pattern was much more consistent with SC stimulation than with MLR stimulation, as it was also shown for SC-evoked sideward walking (see above).

Figure 6, $C$ and $D$, shows the trajectory of the left foot in one of the steps $(C)$ and 10 approximated stance trajectories (D) of cat 4 (treadmill angle $\alpha=45^{\circ} \mathrm{R}$ ). The variability of trajectories was much smaller than in the MLR-evoked walking (Fig. 6B). All stance trajectories were parallel to the velocity vector; the mean angle of the stance trajectory in cat 4 was $0^{\circ}$ (red interrupted line). Similar results were obtained in all tested cats (Fig. 4, bar 4; Table 1, column $45^{\circ}$ ).

Again, as with $90^{\circ}$, one can conclude that the SC-evoked locomotion was well adapted to the treadmill motion at $45^{\circ}$, and can be termed the diagonal walking. A striking difference between MLR- and SCevoked walking was also reflected in different EMG patterns (see below).

\section{Comparison of EMG patterns of MLR- and SC-evoked locomotion at treadmill angles 0,45 , and $90^{\circ}$}

Figure 7 shows an average activity in four muscles of the right limb as a function of the step phase (see Materials and Methods). Recordings were performed in five tests with different treadmill direction (cat 4). Locomotion was evoked by MLR stimulation $(A)$ and SC stimulation $(B)$. The structure of locomotor cycle during forward walking (treadmill angle $0^{\circ}$ ) evoked by MLR and SC stimulation was similar: the swing terminated at phase 0.35-0.38. In both MLR- and SCevoked walking at treadmill angles 45 and $90^{\circ}$, the structure of the cycle in leading and trailing limbs was different. The swing was longer (up to 0.54 ) in the trailing limb (Fig. $7 A, B, 45^{\circ} \mathrm{R}, 90^{\circ} \mathrm{R}$ ), and shorter (down to 0.25 ) in the leading limb (Fig. $7 A, B, 45^{\circ} \mathrm{L}, 90^{\circ} \mathrm{L}$ ). These changes in cycle structure were most likely caused by limb collisions. Similar results were obtained in all eight tested cats.
These data show that, during the stance phase, the foot was sliding on the support surface. For this reason, one can conclude that MLR-evoked walking was poorly adapted to the treadmill motion (Table 1 , column $45^{\circ}$ ).

\section{MLR stimulation}

From Figure $7 A$ one can see that phasing of individual muscles in the step cycle only weakly depended on the direction of treadmill motion: the EMG burst of Tib-R was timed to the swing phase of 
the right limb, whereas the EMG bursts of Gast-R, Glut-R, and Add-R were mostly confined to the stance phase. In contrast, the magnitude of EMG activity depended on the treadmill direction, especially in Glut- $R$, in which it was much larger with the limb leading $\left(\alpha=45^{\circ} \mathrm{L}\right.$ and $\left.90^{\circ} \mathrm{L}\right)$ than with the limb trailing ( $\alpha=$ $45^{\circ} \mathrm{R}$ and $\left.90^{\circ} \mathrm{R}\right)$. A similar but weaker dependence was observed in Add-R. Similar EMG patterns were observed in the other three cats with MLR-evoked locomotion.

\section{SC stimulation}

Figure $7 B$ shows average EMG activity during SC-evoked locomotion. The EMG waveforms during forward walking ( $\alpha=$ $0^{\circ}$ ) were basically similar to those during MLR-evoked locomotion (Fig. 7A): the EMG burst of Tib-R was timed to the swing phase of the right limb, whereas the EMG bursts of Gast-R, Glut-R, and Add-R were mostly confined to its stance phase. However, the EMG waveforms during walking in other directions differed markedly from those during MLRevoked locomotion. The main difference was that the activity of muscles during SCevoked locomotion was much less confined to a definite phase of the step cycle. For example, Tib-R was active mainly during swing of the right limb at $\alpha=0^{\circ}$ and $45^{\circ} \mathrm{L}$, in the end of swing and beginning of stance at $\alpha=90^{\circ} \mathrm{L}$, and at the end of swing and during stance at $\alpha=45^{\circ} \mathrm{R}$, $90^{\circ} \mathrm{R}$. Similarly, Gast-R had a peak in the early stance at $\alpha=0^{\circ}, 45^{\circ} \mathrm{L}, 45^{\circ} \mathrm{R}$, and $90^{\circ} \mathrm{L}$, but it was active in the late stance and early swing at $\alpha=90^{\circ} \mathrm{R}$. Glut-R was active in stance at $\alpha=0^{\circ}, 45^{\circ} \mathrm{L}$, and $90^{\circ} \mathrm{L}$, but it was active in swing at $\alpha=45^{\circ} \mathrm{R}$ and $90^{\circ} \mathrm{R}$. One can also see that the treadmill direction affected the EMG magnitude (e.g., in Glut-R, Gast-R). The EMG patterns in other cats $(N=4)$ were basically similar to that in cat 4 , though some differences in the peak EMG and its phasing could be found.

To summarize, during MLR-evoked locomotion, the EMG patterns for all directions of walking were basically similar to those of forward walking. During diagonal and sideward treadmill motion, these EMG patterns resulted in limb movements that were not aligned to the treadmill direction. In contrast, during SC-evoked locomotion, limb movements were aligned to the direction of treadmill motion. This was caused by considerable modifications of EMG patterns compared with forward walking.

\section{Backward, in-place, and air stepping}

Figure $8 A$ shows an example of the effects of MLR stimulation under different support conditions in cat 5 . Initially, the treadmill was moving backward $\left(\alpha=0^{\circ}\right)$, and the cat was walking forward. Then the treadmill was stopped, and stepping movements discontinued. Then the treadmill started moving forward $(\alpha=$ $\left.180^{\circ}\right)$, and stepping movements were absent. Finally, the treadmill started moving backward $\left(\alpha=0^{\circ}\right)$, and forward walking

\section{Treadmill $45^{\circ} \mathrm{R}$}

\section{MLR stimulation}

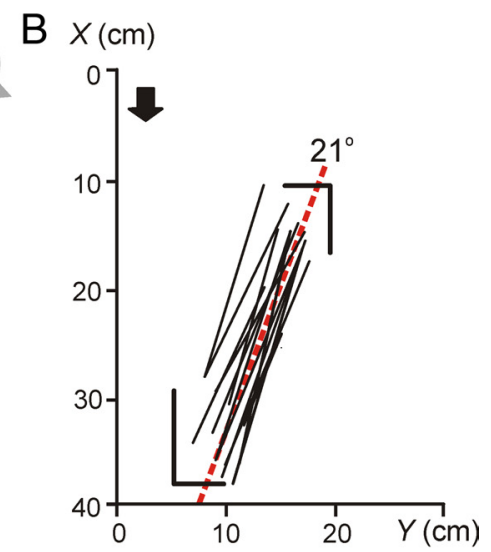

SC stimulation
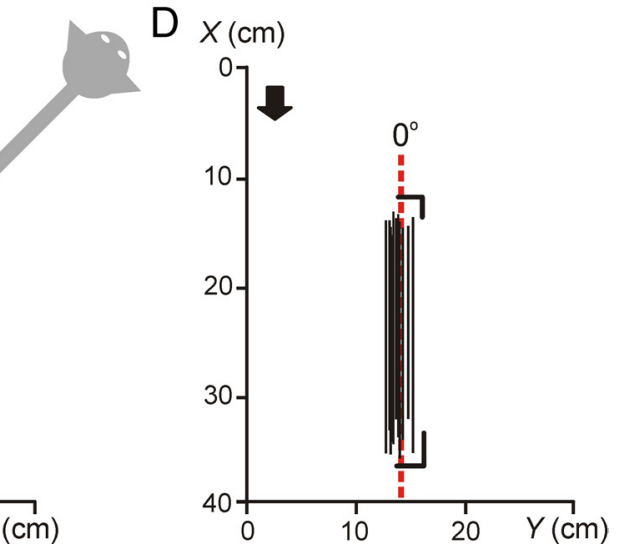

Figure 6. Locomotion evoked by MLR stimulation $(A, B)$ and SC stimulation $(C, D)$ in cat 4 on the treadmill moving at $\alpha=45^{\circ} \mathrm{R}$. $A, C$, Sequential positions of the left foot during one step cycle. $\boldsymbol{B}, \boldsymbol{D}$, Approximated stance trajectories in 10 sequential step cycles of the left limb, as well as the mean value of their S-V angles (red interrupted line). Symbols and designations as in Figure 3.

resumed. With MLR stimulation, neither backward walking (at $\alpha=180^{\circ}$ ) nor in-place stepping were observed in any of four tested cats.

Figure $8, B-G$, shows the effects of SC stimulation under the same support conditions in cat 2. Like MLR stimulation (Fig. 8A), SC stimulation evoked forward walking $\left(\alpha=0^{\circ}\right.$; Fig. $8 B, C)$. Unlike MLR stimulation, however, SC stimulation evoked backward walking ( $\alpha=180^{\circ}$; Fig. $8 D, E$ ). Stepping limb movements were rather uniform, with the step cycle duration of $0.6-0.7 \mathrm{~s}$, the step length $7-11 \mathrm{~cm}$, i.e., much smaller than during forward walking. The peak contact force $(0.3-0.5$ $\mathrm{kg}$ ) was also smaller than during forward walking. The right and left limbs were stepping in antiphase. These characteristics of backward locomotor pattern were similar to those described earlier for intact (Buford and Smith, 1990; Buford et al., 1990; Zelenin et al., 2011) and decerebrate cats (Musienko et al., 2007).

Figure $8 E$ shows a side view of the left foot trajectory during one step cycle of backward walking. In the stance phase (filled circles, 1-7), the foot moved from the extreme posterior position to the extreme anterior position. In the swing phase, the foot rapidly returned to the extreme posterior position (empty circles, 7-15). One can see that the limb locomotor movements were performed in much more rostral position in relation to the body 
A

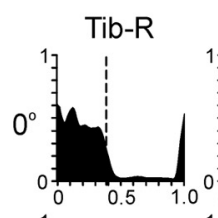

MLR stimulation
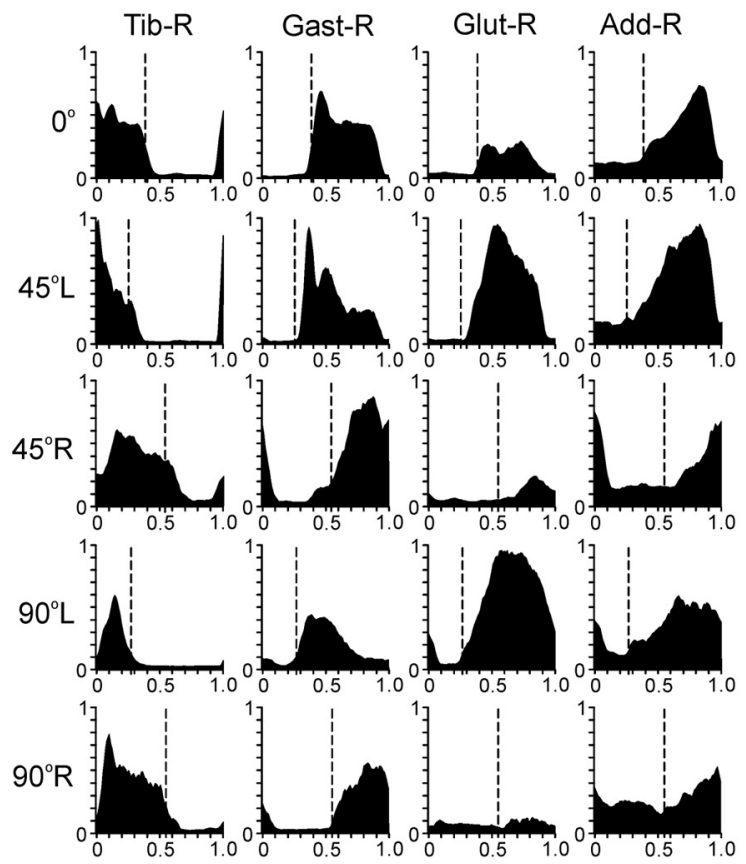
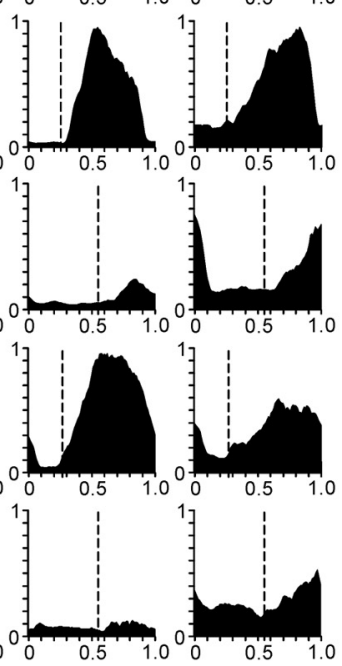

B
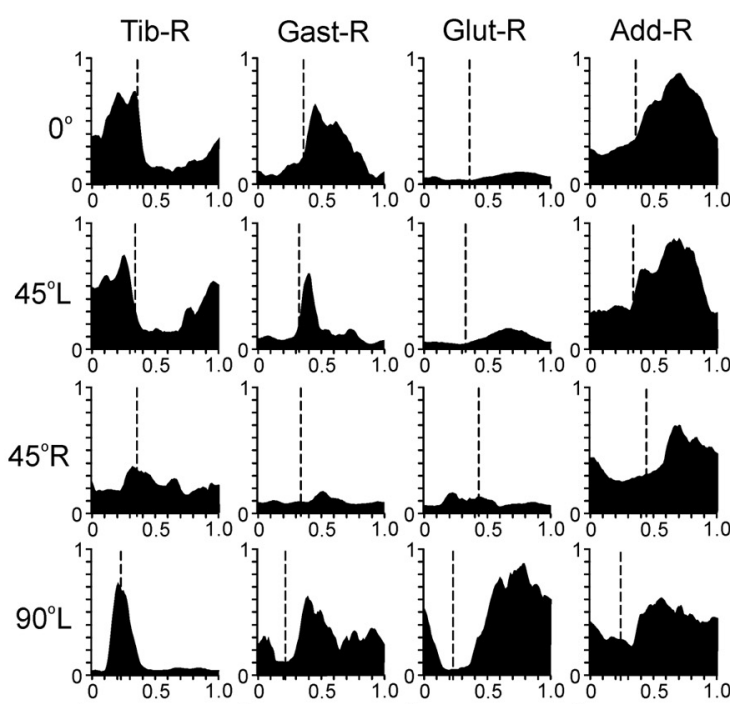

$90^{\circ} \mathrm{R}$
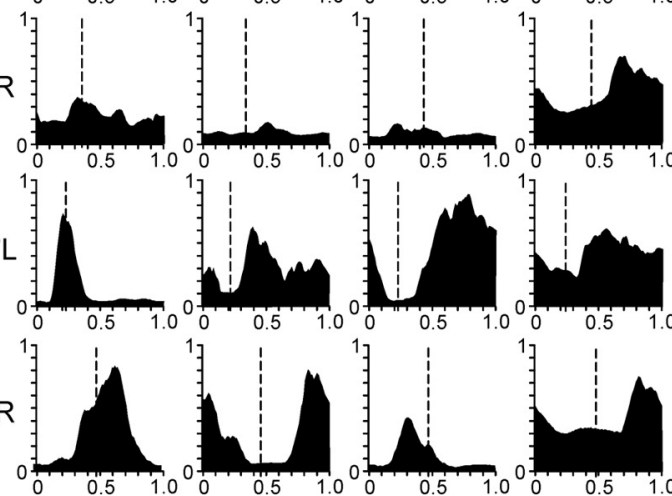

Figure 7. EMG patterns of MLR-evoked $(\boldsymbol{A})$ and SC-evoked locomotion $(\boldsymbol{B})$ in cat 4 at treadmill angles 0,45 , and $90^{\circ}$. At each treadmill angle, EMGs of the right limb muscles were averaged ove 10 sequential step cycles. The step cycle was normalized to 1.0; the beginning of the swing phase was taken as the cycle onset and the swing termination is indicated by an interrupted line. Abscissa: phase of step cycle; ordinate: EMG (A.U.).

compared with movements during forward walking (Fig. 8C,E). The stance trajectories were found to be parallel to the treadmill velocity vector and the body axis (data not shown), suggesting that backward walking was well adapted to the treadmill motion. Similar results were obtained in all backward walking cats. Backward walking was observed in four of seven tested animals (Table 1 , column $180^{\circ}$ ).

If the treadmill belt did not move, SC stimulation evoked in cat 2 "in-place stepping" (Fig. $8 F, G$ ), characterized by the following: (1) alternating EMG activity of the right and left limbs (period $\sim 1 \mathrm{~s}$ ), (2) reciprocal flexor and extensor bursts in each limb, (3) vertical oscillations of the foot that resulted in the periodicity of a ground reaction force under the limb, and (4) absence of horizontal foot displacements during the movement cycle (Fig. $8 G)$. In-place stepping was observed in four of six tested cats. In two cats, in-place stepping of only one limb was observed. In all four cats, in-place stepping limb movements had characteristics similar to those in cat 2.

If the treadmill supporting the limbs was removed, both MLR stimulation and SC stimulation could evoke "air stepping," but characteristics of limb movements under these two conditions were very different. Figure $9 \mathrm{~A}$ shows one cycle of air stepping in cat 4 with MLR and SC stimulation. One can see that the magnitude of limb oscillations (angle between extreme anterior and posterior limb positions, $S$ ) was much larger with MLR stimulation than with SC stimulation, whereas the cycle duration with MLR stimulation was shorter. When averaged over all cats exhibiting air stepping, these values were significantly different: the magnitude of oscillations was $44 \pm 15^{\circ}$ against $16 \pm 5^{\circ}$, and the cycle duration was $0.51 \pm 0.11 \mathrm{~s}$ against $0.81 \pm 0.22 \mathrm{~s}$ (Fig. 9B). The EMG patterns of air stepping under the two conditions also differed. Alternation of flexor and extensor bursts in each limb was seen clearer with MLR stimulation than with SC stimulation
(Fig. 9, compare $C, D$ ). With SC stimulation, in-phase bursts in antagonistic muscles were sometimes observed. Air stepping was evoked by MLR stimulation in three of four tested cats, and by SC stimulation in three of six cats.

\section{Discussion}

In the present study, we compared locomotion in decerebrate cats evoked by MLR and SC stimulation. MLR stimulation primarily activates brainstem locomotor circuits that, through descending pathways, activate and modulate individual spinal limb controllers (for review, see Arshavsky et al., 1986; Orlovsky et al., 1999). In contrast, stimulation of the spinal cord can immediately activate limb controllers (as demonstrated in spinal animals; Barthélemy et al., 2007; Courtine et al., 2009). One cannot exclude, however, that SC stimulation in decerebrate animals, through ascending pathways, can activate brainstem circuits sending commands to the spinal cord (spino-bulbo-spinal loop). Nevertheless, it seems likely that MLR- and SC-evoked locomotion strongly differ in the contribution of spinal and supraspinal mechanisms to activation and modulation of limb controllers. Comparison of forward locomotion in decerebrate cats, evoked by MLR and SC stimulation, was first done by Iwahara et al. (1992). They demonstrated a close similarity between two locomotor patterns. However, a striking difference between the two patterns was found in the present study when comparing locomotion not only forward but also in other directions.

We found that SC-evoked stepping could be oriented in different directions relative to the longitudinal body axis, depending on the direction of treadmill motion. Thus, the direction of stepping was determined by external conditions. Similar results were obtained in chronic spinal rats walking on the treadmill that moved backward, forward, or sideward (Courtine et al., 2009; 
A

\section{$\underline{\text { MLR stimulation }}$}

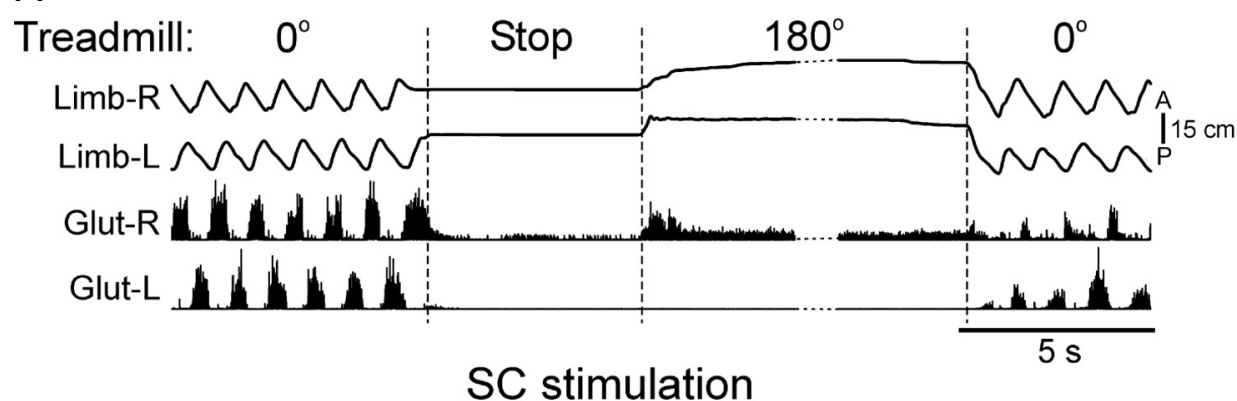

B Treadmill $0^{\circ}$

C

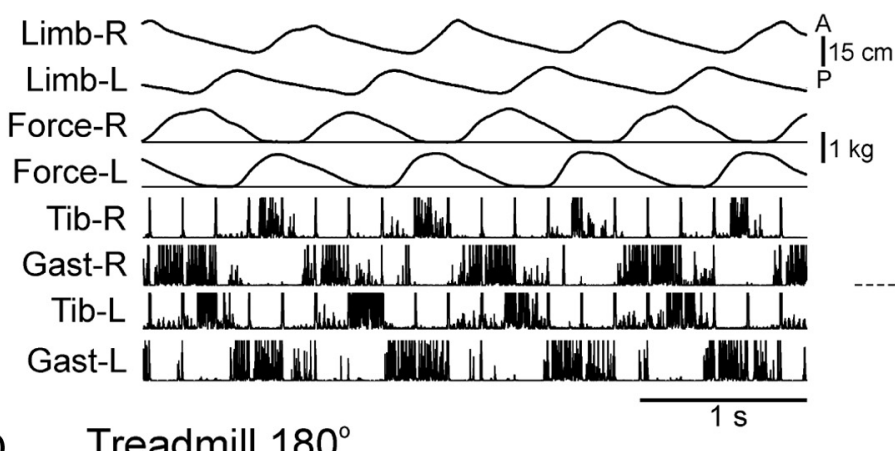

D Treadmill $180^{\circ}$

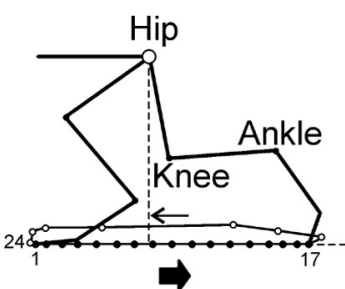

Limb-R C

Force-R

Force-L

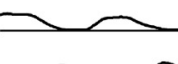

Tib-R

||W|

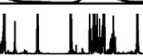

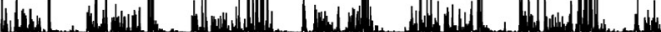

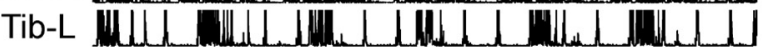

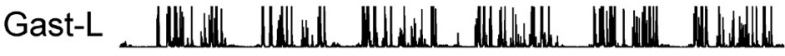

F Treadmill: Stop

$1 \mathrm{~s}$

Limb-R

Limb-L

西

Force-R
Force-L

Tib-R

Gast-R

,

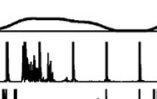

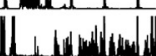

Nin

Gast-L
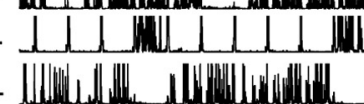
l $1 \mathrm{~kg}$

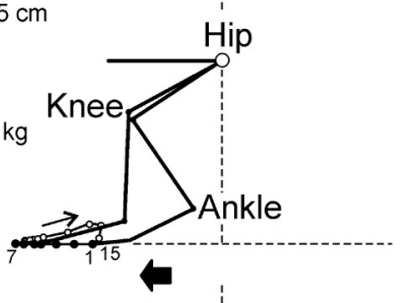

$E$

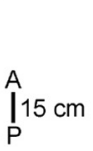

G

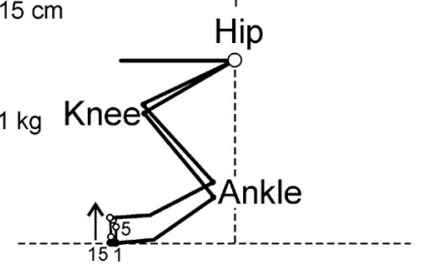

Figure 8. Comparison of locomotor effects of MLR and SC stimulation under different support conditions. $A$, Example of the effects of MLR stimulation in cat 5 under three conditions: treadmill moved backward $\left(0^{\circ}\right)$, did not move (Stop), moved forward $\left(180^{\circ}\right)$ and then backward again $\left(0^{\circ}\right) . B-G$, Examples of locomotor effects of $S C$ stimulation in cat 2 under three conditions: treadmill moved backward $(\boldsymbol{B}, \boldsymbol{C})$, forward $(\boldsymbol{D}, \boldsymbol{E})$, and did not move $(\boldsymbol{F}, \boldsymbol{G}) . \boldsymbol{C}, \boldsymbol{E}, \boldsymbol{G}$, Sequential positions of the left foot during one step cycle. Extreme limb positions are shown. Symbols and designations as in Figure 3.

Shah et al., 2012). SC-evoked backward locomotion was also observed in spinal and decerebrate cats (Gerasimenko et al., 2005; Musienko et al., 2007).

We found that SC-evoked stepping could be performed not only in the principal body planes and directions (forward, back-

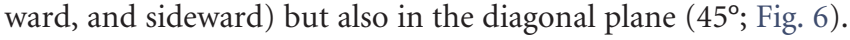
This finding suggests that each limb controller can generate a continuous spectrum of the forms of locomotion differing in the direction of stepping, rather than a few discrete forms. This view has been supported by the finding (Lamb and Yang, 2000; Pang and Yang, 2002) that infants (whose limb control mechanisms are situated at the lower CNS levels) are capable of stepping in different directions, with no discrete differences in either the EMG patterns or the temporal parameters of stepping, as the 


\section{Air stepping}

A

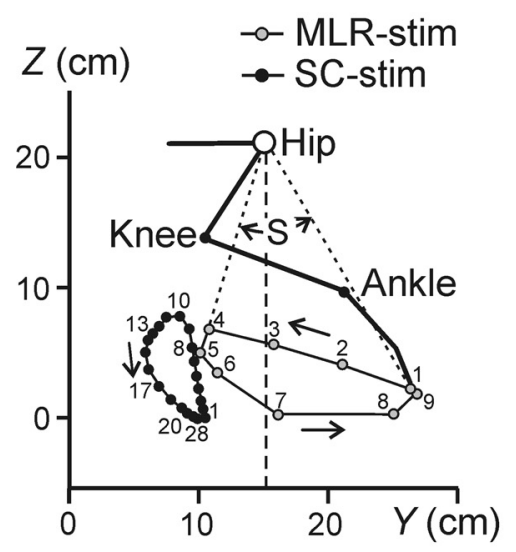

B

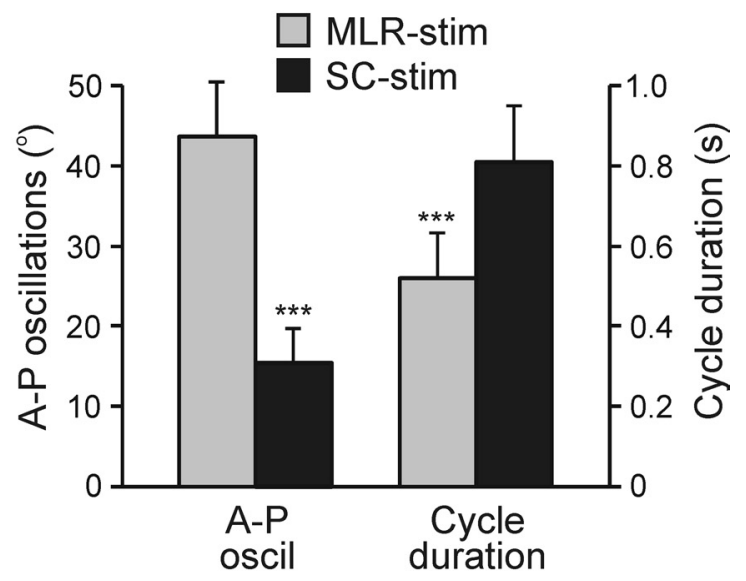

C MLR stimulation

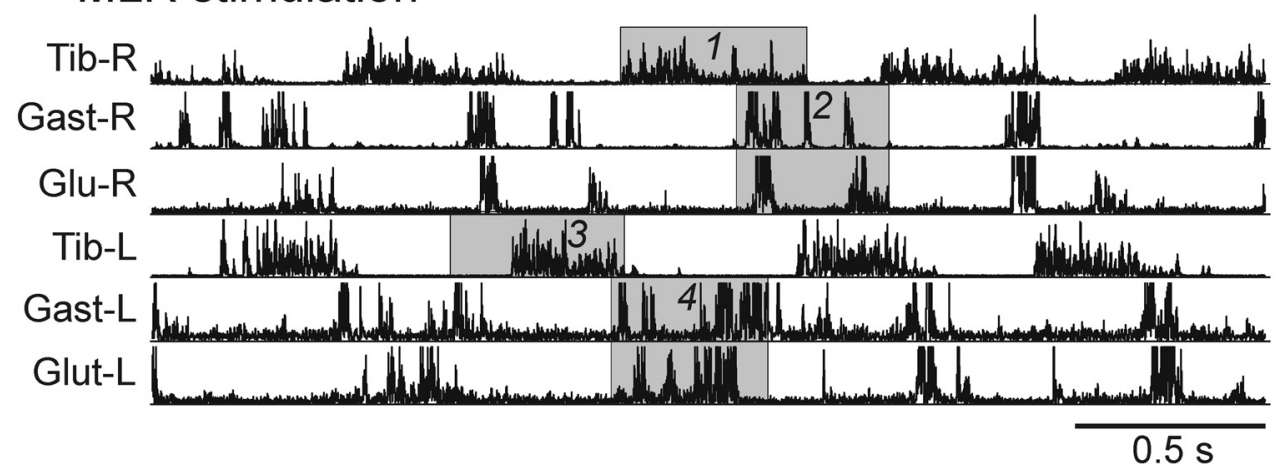

D SC stimulation

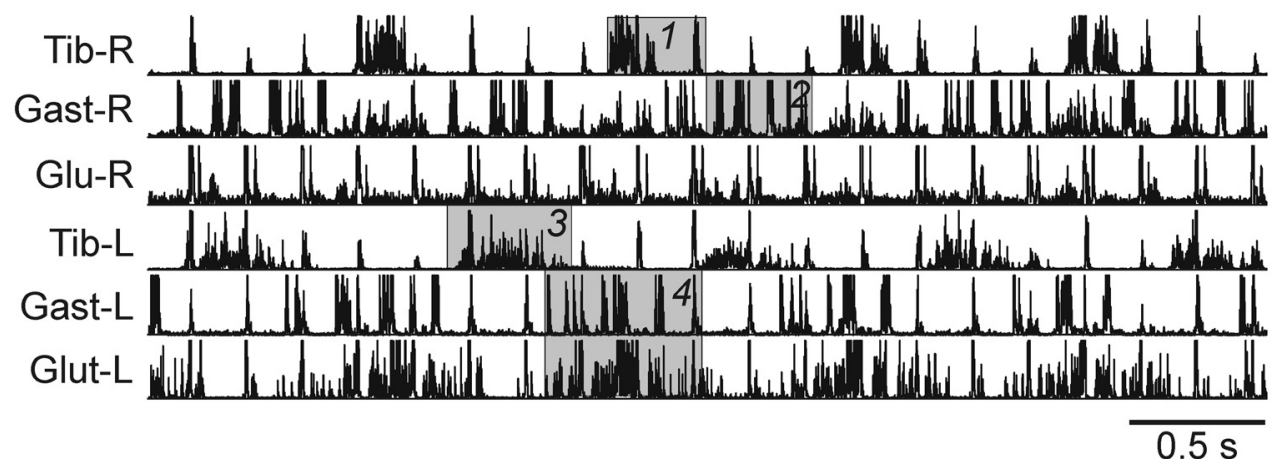

Figure 9. Comparison of air stepping evoked by MLR and SC stimulation. $A$, Sequential positions of the right foot during one cycle of air stepping evoked by MLR stimulation (gray circles) and by SC stimulation (black circles) in cat 4. Arrows show the directions of foot movement. Angle S characterizes the magnitude of A-P oscillations (A-P oscil) of the limb. B, Characteristics of air stepping averaged in three cats with MLR stimulation and in three cats with SC stimulation, over 36 and 59 step cycles, respectively (mean \pm SD; indication of significance level: $\left.{ }^{* * *} p<0.001\right)$. C, $\mathbf{D}$, EMG activity during air stepping evoked by MLR stimulation ( $\boldsymbol{C}$ and SC stimulation (D). The phases of flexor activity ( 1 and 3 ) and extensor activity ( 2 and 4 ) are highlighted. Symbols and designations as in Figures 2 and 3 .

direction of stepping was gradually changed. A large diversity of the directions of stepping is characteristic for many other legged animals, e.g., crustaceans (Larimer, 1976; Ayers and Clarac, 1978).

In contrast to SC stimulation, MLR stimulation evoked coordinated stepping movements only if the treadmill was moving in the front-to-rear direction (Fig. 2A). With all other angles of treadmill motion, stepping movements were dramatically distorted or absent (Figs. 5A, 6A, 8A). The analysis of these distortions suggests that the limb controllers, when activated from
MLR, generate motor commands for forward stepping, irrelevant to treadmill motion.

These suggestions were supported in air stepping experiments. During air stepping evoked by MLR stimulation, the limb controller generates limb oscillations with a large A-P component (Fig. 9A, $B$ ), comparable to the step length during treadmill forward walking (Fig. $2 A$ ). We suggest that the spinal circuits generating this A-P component are activated by MLR-evoked supraspinal commands during treadmill locomotion as well, and thus determine the forward direction of walking. 
A

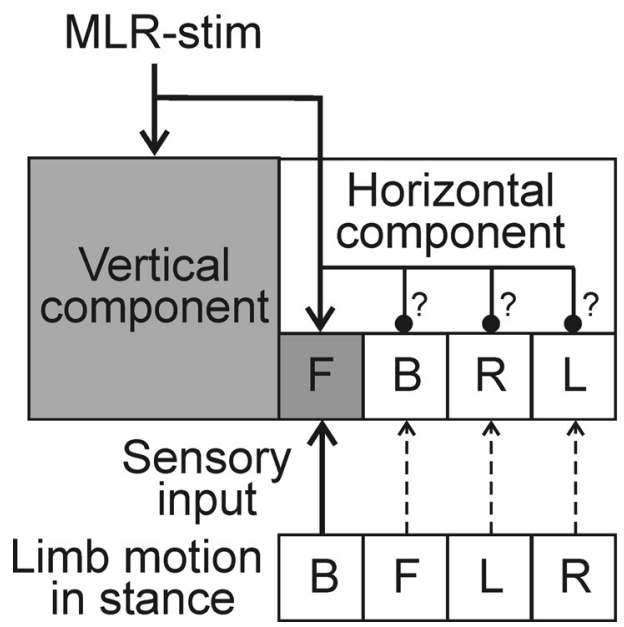

$\mathrm{B}$

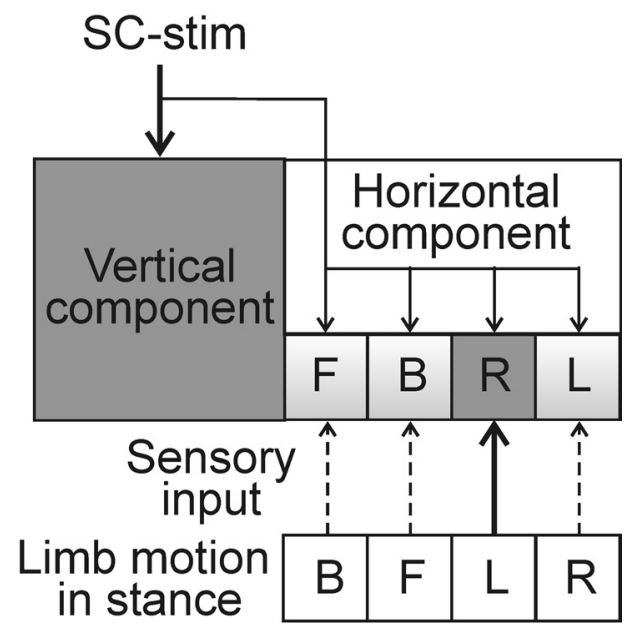

Figure 10. Basic mechanisms for the control of step direction. $A$, Elicitation of stepping by MLR stimulation. Question marks indicate inhibitory connections that are not a necessary condition for the model functioning. $\boldsymbol{B}$, Elicitation of stepping by SC stimulation. Activation of a given mechanism, gray; subthreshold activation, light gray; inhibition, white. See Discussion for explanation. F, forward; B, backward; R, rightward; L, leftward.

In contrast, during air stepping evoked by SC stimulation, the limb controller generates much smaller limb oscillations, without a large component in A-P direction (as in MLR-evoked air stepping, Fig. $9 A, B)$ or in any other horizontal direction. The horizontal component was practically absent during in-place stepping (Fig. $8 F$ ). Thus, SC stimulation itself does not cause any directionality in the limb trajectory. A large horizontal component in limb oscillations appears only after positioning the limb on the moving treadmill, and the direction of treadmill motion (monitored by sensory input from the limb during stance) determines the direction of stepping. This is not possible in MLRstimulated cats, in which the forward direction of stepping is determined by supraspinal commands.

The MLR can thus be considered as a command center for elicitation of forward locomotion. This form of locomotion is vitally important for animals and humans as the main form of subject's progression. We suggest that function of supraspinal commands, initiated by MLR stimulation and transmitted by descending pathways, is to select and activate only one of numerous forms of operation of limb controllers, namely, forward walking. The viewpoint that different motor patterns can be produced by the same circuitry given the appropriate modulatory mechanism was considered by a number of authors (Gelfand et al., 1988; Marder and Calabrese, 1996; Shah et al., 2012). One can hypothesize that some other forms of locomotion (e.g., backward and sideward walking) also have their command centers.

As shown in the present study, walking in different directions evoked by SC stimulation is accompanied by considerable changes in the pattern of limb movements and muscular activity. First, during stepping that includes a lateral component (sideward and diagonal walking), the leading and trailing limbs have very different motor patterns, including the step magnitude and EMG profiles (Figs. 5C,7B). Second, the functional role of individual muscles may radically change, depending on the direction of stepping. For example, the right hip adductor (Fig. 7B, Add-R) may contribute to the transfer of the right limb during leftward walking, but to the stance of this limb during rightward walking. The contribution of a given muscle to the limb transfer or to the limb stance may change gradually when the direction of stepping is changing, as, e.g., in Glut-R (compare Fig. 7B, Glut-R at $\alpha=0$,
45, and $90^{\circ}$ ). Gradual changes in EMG patterns when walking in different directions were earlier demonstrated in human infants (Lamb and Yang, 2000; Pang and Yang, 2002). However, for a comprehensive description of limb stepping in different directions, one needs much more information about activity of numerous limb muscles, movements at different joints, etc.

Analysis of forward walking in the spinal cat exposed a number of neural mechanisms responsible for the transition from one phase of the step cycle to the other phase (e.g., Grillner and Rossignol, 1978). A critical point in the step cycle is onset of the swing phase. The most important factor for triggering swing is reaching by the limb a definite caudal position (e.g., a critical angle of hip extension). The other factors include unloading the limb, influences from the opposite limb, influences from the central pattern generator (Grillner, 1973, 1975; Grillner and Zangger, 1979; Orlovsky et al., 1999), etc. To extend this concept of swing generation on other directions of stepping, one can suggest that the swing onset is determined by the afferents signaling a critical limb deviation in the stance phase. For example, during sideward walking, the afferent signals about hip adduction and abduction could be used for triggering the swing in opposite direction.

Steps in different directions are often used by animals and humans for the maintenance of balance during standing and during locomotion. Large postural perturbations during standing, caused by lateral tilt of the support or lateral push, can elicit lateral step in rabbit and cat (Beloozerova et al., 2003; Karayannidou et al., 2009). A step with lateral component can also be elicited by a large postural perturbation in standing humans (Chvatal et al., 2011). Also, in the cat walking forward, a step deviated from the direction of progression (to the right or to the left) is used for correcting the perturbations of balance (Karayannidou et al., 2009). One can suggest that common spinal mechanisms are used for the generation of a single step during postural corrections, as well as for the generation of repetitive steps during locomotion.

To conclude, we propose a hypothesis about control of step direction (Fig. 10A). A limb controller (Orlovsky et al., 1999) includes two principal mechanisms, one generating a vertical component of step (limb elevation and lowering), and the other generating a horizontal component (limb transfer from one ex- 
treme point to the other). The latter includes circuits generating the horizontal component of step in different directions (for simplicity, Fig. 10 shows only the circuits generating steps in four directions: F, forward; B, backward; R, rightward; L, leftward). These circuits receive sensory input signaling limb motion in stance; reaching an extreme position triggers a limb transfer.

MLR stimulation (Fig. 10A) activates a mechanism generating the vertical component of step, selects and activates the circuit $\mathrm{F}$ that will transfer the limb forward during swing and backward during stance, and possibly inhibits all other circuits $(B, R$, and L). The sensory input signaling backward limb deviation during stance assists triggering the limb transfer. Thus, MLR stimulation evokes forward stepping independently of the direction of treadmill motion.

SC stimulation (Fig. 10B) activates a mechanism generating the vertical component of step. It also causes subthreshold activation of all circuits generating the horizontal component. Due to the treadmill motion (e.g., to the left), the limb will reach an extreme left position, and sensory input will activate circuit $\mathrm{R}$, which will evoke rightward step. Thus, SC stimulation can evoke stepping opposite to treadmill motion.

\section{References}

Arshavsky YI, Gelfand IM, Orlovsky GN (1986) Cerebellum and rhythmical movements. Springer, New York.

Ayers JL, Clarac F (1978) Neuromuscular strategies underlying different behavioral acts in a multi-functional crustacean leg joint. J Comp Physiol 128:81-94. CrossRef

Barthélemy D, Leblond H, Rossignol S (2007) Characteristics of mechanisms of locomotion induced by intraspinal microstimulation and dorsal root stimulation in spinal cats. J Neurophysiol 97:1986-2000. CrossRef Medline

Beloozerova IN, Zelenin PV, Popova LB, Orlovsky GN, Grillner S, Deliagina TG (2003) Postural control in the rabbit maintaining balance on the tilting platform. J Neurophysiol 90:3783-3793. CrossRef Medline

Buford JA, Smith JL (1990) Adaptive control for backward quadrupedal walking. II. Hindlimb muscle synergies. J Neurophysiol 64:756-766. Medline

Buford JA, Zernicke RF, Smith JL (1990) Adaptive control for backward quadrupedal walking. I. Posture and hindlimb kinematics. J Neurophysiol 64:745-755. Medline

Chvatal SA, Torres-Oviedo G, Safavynia SA, Ting LH (2011) Common muscle synergies for control of center of mass and force in nonstepping and stepping postural behaviors. J Neurophysiol 106:999-1015. CrossRef Medline

Courtine G, Gerasimenko Y, van den Brand R, Yew A, Musienko P, Zhong H, Song B, Ao Y, Ichiyama RM, Lavrov I, Roy RR, Sofroniew MV, Edgerton VR (2009) Transformation of nonfunctional spinal circuits into functional states after loss of brain input. Nat Neurosci 12:1333-1342. CrossRef Medline

Deliagina TG, Popova LB, Grant G (1997) The role of tonic vestibular input for postural control in rats. Arch Ital Biol 135:239-261. Medline

Deliagina TG, Musienko PE, Zelenin PV, Lyalka VF, Orlovsky GN, Gerasimenko YP (2012) Spinal and supraspinal control of the direction of stepping during locomotion. Soc Neurosci Abstr 38:577.27.

Garcia-Rill E, Skinner RD (1987a) The mesencephalic locomotor region. i. Activation of a medullary projection site. Brain Res 411:1-12. CrossRef Medline

Garcia-Rill E, Skinner RD (1987b) The mesencephalic locomotor region. ii. Projections to reticulospinal neurons. Brain Res 411:13-20. CrossRef Medline

Gelfand IM, Orlovsky GN, Shik ML (1988) Locomotion and scratching in tetrapods. In: Neural control of rhythmic movements in vertebrates (Cohen AH, Rossignol S, Grillner S eds), pp 167-199. New York: Wiley.

Gerasimenko YP, Avelev VD, Nikitin OA, Lavrov IA (2003) Initiation of locomotor activity in spinal cats by epidural stimulation of the spinal cord. Neurosci Behav Physiol 33:247-254. CrossRef Medline

Gerasimenko YP, Lavrov IA, Bogacheva IN, Shcherbakova NA, Kucher VI, Musienko PE (2005) Formation of locomotors patterns in decerebrate cats in conditions of epidural stimulation of the spinal cord. Neurosci Behav Physiol 35:291-298. CrossRef Medline

Gerasimenko Y, Musienko P, Bogacheva I, Moshonkina T, Savochin A, Lavrov I, Roy RR, Edgerton VR (2009) Propriospinal bypass of the serotonergic system that can facilitate stepping. J Neurosci 29:5681-5689. CrossRef Medline

Grillner S (1973) Locomotion in the spinal cat. In: Control of posture and locomotion (Stein RB, Pearson KG, Smith RS, Redford JB, ed) pp 515535. New York: Plenum.

Grillner S (1975) Locomotion in vertebrates-central mechanisms and reflex interaction. Physiol Rev 55:247-304. Medline

Grillner S, Rossignol S (1978) On the initiation of the swing phase of locomotion in chronic spinal cats. Brain Res 146:269-277. CrossRef Medline

Grillner S, Zangger P (1979) On the central generation of locomotion in the low spinal cat. Exp Brain Res 34:241-261. Medline

Iwahara T, Atsuta Y, Garcia-Rill E, Skinner RD (1992) Spinal cord stimulation-induced locomotion in the adult cat. Brain Res Bull 28:99_ 105. Medline

Jordan LM (1986) Initiation of locomotion from the mammalian brainstem. In Neurobiology of vertebrate locomotion (Grillner S, Stein PSG, Stuart DG, Forssberg H, eds), pp. 21-37. London: Macmillan.

Karayannidou A, Zelenin PV, Orlovsky GN, Sirota MG, Beloozerova IN, Deliagina TG (2009) Maintenance of lateral stability during standing and walking in the cat. J Neurophysiol 101:8-19. Medline

Lamb T, Yang JF (2000) Could different directions of infant stepping be controlled by the same locomotor central pattern generator? J Neurophysiol 83:2814-2824. Medline

Larimer O (1976) Command interneurons and locomotor behavior in crustaceans. In Neural control of locomotion (Herman RM, Grillner S, Stein PSG, Stuart D, eds), pp 293-326. New York: Plenum.

Marder E, Calabrese RL (1996) Principles of rhythmic motor pattern generation. Physiol Rev 76:687-717. Medline

Musienko PE, Bogacheva IN, Gerasimenko YP (2007) Significance of peripheral feedback in the generation of stepping movements during epidural stimulation of the spinal cord. Neurosci Behav Physiol 37:181-190. CrossRef Medline

Musienko P, Courtine G, Tibbs JE, Kilimnik V, Savochin A, Garfinkel A, Roy RR, Edgerton VR, Gerasimenko Y (2012) Somatosensory control of balance during locomotion in decerebrated cat. J Neurophysiol 107:2072-2082. CrossRef Medline

Orlovsky GN, Deliagina TG, Grillner S (1999) Neuronal control of locomotion. From mollusc to man. Oxford UP.

Pang MY, Yang JF (2002) Sensory gating for the initiation of the swing phase in different directions of human infant stepping. J Neurosci 22:5734-5740. Medline

Rossignol S (1996) Neural control of stereotypic limb movements. In: Handbook of physiology (Rowell LB, Sheperd JT, eds), pp 173-216. New York: Oxford UP

Shah PK, Gerasimenko Y, Shyu A, Lavrov I, Zhong H, Roy RR, Edgerton VR (2012) Variability in step training enhances locomotor recovery after a spinal cord injury. Eur J Neurosci 36:2054-2062. CrossRef Medline

Sherrington CS (1906) The integrative action of the nervous system. New Haven: Yale UP.

Shik ML, Orlovsky GN (1976) Neurophysiology of locomotor automatism. Physiol Rev 56:465-501. Medline

Shik ML, Severin FV, Orlovsky GN (1966) Control of walking and running by means of electrical stimulation of the mid-brain. Biophysics 11:756-765.

Stein PSG, Mortin LI, Robertson GA (1986) The forms of a task and their blends. In: Neurobiology of vertebrate locomotion, pp 201-216. London: Macmillan.

Zelenin PV, Deliagina TG, Orlovsky GN, Karayannidou A, Stout EE, Sirota MG, Beloozerova IN (2011) Activity of motor cortex neurons during backward locomotion. J Neurophysiol 105:2698-2714. CrossRef Medline 